2015-11

\title{
Tablet App halometer for the assessment of dysphotopsia
}

Buckhurst, P::0000-0001-6037-0597

http://hdl.handle.net/10026.1/9185

10.1016/j.jcrs.2015.05.041

Journal of Cataract and Refractive Surgery

Ovid Technologies (Wolters Kluwer Health)

All content in PEARL is protected by copyright law. Author manuscripts are made available in accordance with publisher policies. Please cite only the published version using the details provided on the item record or document. In the absence of an open licence (e.g. Creative Commons), permissions for further reuse of content should be sought from the publisher or author. 


\title{
Tablet App halometer for the assessment of dysphotopsia
}

\author{
Phillip J. Buckhurst, PhD, Shehzad A. Naroo, PhD, Leon N. Davies, PhD, Sunil Shah, FRCS,
} Hetal Buckhurst, PhD, Alec Kingsnorth, PhD, Tom Drew, PhD, James S. Wolffsohn, PhD

PURPOSE: To assess the validity and repeatability of the Aston Halometer.

SETTING: University clinic, United Kingdom.

DESIGN: Prospective, repeated-measures experimental study.

METHODS: The halometer comprises a bright light-emitting-diode (LED) glare source in the center of an iPad4. Letters subtending $0.21^{\circ}(\sim 0.3 \operatorname{logMAR})$ were moved centrifugally from the LED in 0.05 degree steps in 8 orientations separated by 45 degrees for each of 4 contrast levels $(1000$, 500,100 , and 25 Weber contrast units $\left[\mathrm{C}_{w}\right]$ ) in random order. Bangerter occlusion foils were inserted in front of the right eye to simulate monocular glare conditions in 20 subjects (mean age $27.7 \pm 3.1$ years). Subjects were positioned 2 meters from the screen in a dark room with the iPad controlled from an iPhone via Bluetooth operated by the researcher. The C-Quant straylight meter was also used with each of the foils to measure the level of straylight over the retina. Halometry and straylight repeatability was assessed at a second visit.

RESULTS: Halo size increased with the different occlusion foils and target contrasts ( $F=29.564$, $P<.001)$ as expected and in a pattern similar to straylight measures $(F=80.655, P<0.001)$. Lower contrast letters showed better sensitivity but larger glare-obscured areas, resulting in ceiling effects caused by the screen's field-of-view, with $500 \mathrm{C}_{\mathrm{w}}$ being the best compromise. Intraobserver and interobserver repeatability of the Aston Halometer was good $\left(500 \mathrm{C}_{\mathrm{w}}\right.$ : 0.84 to 0.93 and 0.53 to 0.73 ) and similar to the straylight meter.

CONCLUSION: The halometer provides a sensitive, repeatable way of quantifying a patientrecognized form of disability glare in multiple orientations to add objectivity to subjectively reported discomfort glare.

J Cataract Refract Surg 2015; 41:2424-2429 @ 2015 ASCRS and ESCRS

A photopic phenomenon, termed dysphotopsia, can be induced by refractive surgery, the extent of which may be related to the ablation profile and pupil size ${ }^{1,2}$ and corneal and crystalline lens opacities, ${ }^{3}$ and is one of the few clinical tests correlated with night-driving performance. ${ }^{4}$ Glare can also result from multifocal intraocular lens (IOL) implantation and is often described as haloes. ${ }^{5}$ This is a major cause of multifocal dissatisfaction ${ }^{6}$ and is largely responsible for a relatively high frequency of multifocal IOL explantations. ${ }^{7}$ To measure the retinal blur circle or halo, several instruments, often referred to as halometers, have been created. These devices quantify the size of a photopic scotoma created by a central glare source, assessing forward light wide angle scatter rather than the narrower straylight. ${ }^{6}$ Early methods to assess halos required patients to draw the outline of the perceived halo produced by a candle at a set distance. 8 Others involve visually, bracketing, the edges of the halo with the examiner's hands, ${ }^{9}$ comparison of their halo with objects of known diameter, ${ }^{10}$ or mechanical movement of a target toward or away from the light source in limited meridians. ${ }^{11}$ Namiki and Tagami $^{12}$ attached a glare source within an Octopus 500E (Haag-Streit) automated perimeter to determine the extent of visual field loss surrounding a central glare source. A similar approach was adopted by Gutiérrez et al., lighting LEDs in sequence in increasing eccentricity from a central glare source. ${ }^{2}$ Many of these technique have not been validated,, 10 have ill-defined repeatability, $2,9,10$ and are unable to identify any differences between multifocal IOLs and monofocal IOLs. ${ }^{9,12}$ 
The halometers described by Lee et al. ${ }^{13}$ and by Allen et al. ${ }^{14}$ both used computer programs, which present a central screen glare source (single white spot or a red cross with a white ring respectively) requiring the subject to circle the perceived photopic phenomenon. These halometers have been used to examine dysphotopsia after multifocal IOL implantation ${ }^{14}$ and after LASIK under physiological ${ }^{13}$ and pharmacological (with a miotic agent) conditions. ${ }^{15}$ Lee et al. ${ }^{15}$ observed good repeatability with their halometer; however, the design used for examining multifocal IOLs was not assessed for repeatability and was found to show similar results with both multifocal IOLs and monofocal IOLs.

Currently, the Glare \& Halo test (Tomey, AG) is the only standardized, commercially available, computerized test used to measure the size of photopic phenomenon. Here, a central white target $15 \mathrm{~mm}$ in size is displayed on a screen (luminance 86.6 candelas $[\mathrm{cd}] / \mathrm{m}^{2}$ ) and the subject is required to place a mark with a mouse at the boundary of the ensuing photopic phenomenon for 12 equidistant orientations separated by 30 degrees surrounding the glare source. The central glare area in degrees is then calculated in accordance with the working distance of the subject. The Glare \& Halo test has been used in 3 studies examining the difference in halo sizes between the arrayrefractive multifocal IOL (Abbott Medical Optics Inc.) and a monofocal IOL with a similar aspheric profile. Pieh et al. ${ }^{16}$ found a significant difference in dysphotopsia between the 2 types of pseudophakic correction $^{16}$; however, 2 earlier studies did not find a significant difference. ${ }^{17,18}$ Repeatability studies have not been conducted with the use of this instrument. Another approach recently demonstrated was software (Halo v1.0) run on a computer designed to quantify discrimination capacity under low-illumination conditions, which will be affected by visual disturbances. The test consists of the discrimination of

Submitted: March 10, 2015.

Final revision submitted: May 1, 2015.

Accepted: May 1, 2015.

From the School of Health Professions (P.J. Buckhurst, H. Buckhurst), University of Plymouth, Plymouth, United Kingdom, Ophthalmic Research Group (Naroo, Davies, Shah, Kingsnorth, Drew, Wolffsohn), Life and Health Sciences, Aston University, Birmingham, United Kingdom, Midland Eye (Shah), Solihull, United Kingdom.

Financial Interest: The app is being commercialized by Aston EyeTech Ltd., in which Drs. Drew and Wolffsohn have a financial interest.

Corresponding author: James S. Wolffsohn, PhD, School of Life and Health Sciences, Aston University, Birmingham B4 7ET, UK. E-mail: j.s.w.wolffsohn@aston.ac.uk. customizable luminous peripheral stimuli around a more luminous central one (the glare source) at 3 positions along 12 axes to calculate a visual-disturbance index. It has been shown to be sensitive to retinal disease, ${ }^{19}$ cataract, $^{20}$ age, $^{20}$ and myopic LASIK,, ${ }^{21}$ but repeatability studies have not been published.

The aim of the study is to validate the Aston Halometer, a new halometer with a bright LED central target and performed on a standard mobile tablet designed to be able to quantify and analyze the extent of dysphotopsia in multiple directions of gaze.

\section{PATIENTS AND METHODS}

The experimental study instrument validation required patients with clear media using filters to induce standard amounts of glare to assess the accuracy and reliability of the halometer; hence, 20 young subjects ( 10 men, 10 women) of mean age $27.7 \pm 3.1$ years were recruited from Aston University. The inclusion criteria were uncorrected visual acuity of at least $0.10 \log$ MAR in each eye; mean spherical error within $-0.75 \mathrm{D}$ to $+0.75 \mathrm{D}$; spectacle astigmatism less than $0.75 \mathrm{D}$; the absence of any ocular pathology and previous surgery; and an age between 18 and 40 years. Ethical approval was obtained prospectively for this study from the Institutional Review Board, and informed consent was obtained from each subject after explanation of the details of the study and any possible consequences. The study was conducted in accordance with the tenets of the Declaration of Helsinki. Subjects were refracted and fully corrected with contact lenses, if necessary, after a noncycloplegic subjective refraction, with the end point of the maximum plus prescription consistent with optimum visual acuity.

The C-Quant provides a measure of the level of straylight (forward light scatter) over the retina. Straylight originates from the scattering of light and creates a veil over the vision that is known to increase with age, ocular pathology, and with refractive surgery. ${ }^{22}$ With the C-Quant straylight meter (Oculus), 3 repeats are necessary to achieve an accurate measurement of straylight, and measurement of straylight was considered reliable if the estimated standard deviation was below 0.8 and the quality factor for the psychometric sampling (Q) was above $1.00 .^{23}$

The Aston Halometer provides a measure of the degree of obscuration of a target from a glare source, measured in degrees. It comprises a bright light-emitting diode (LED; Golden Dragon Plus LCW W5AM.PC; 5000K color temperature; pulse width modulation duty cycle of $15.6 \%$, forward current $40 \mathrm{~mA}, 3.7 \mathrm{~V}$; Osram Licht AG) in the center of an iPad4 (Apple), with a $2048 \times 1536$ pixel resolution and a $240 \times 169.5 \mathrm{~mm}$ screen (Figure 1). Subjects were positioned 2 meters from the screen $(6.8 \times 5.6$ degrees field of view $)$ with the iPad controlled from an iPhone over Bluetooth operated by the researcher. Halometry was conducted in a dark room with the halometer as the only light source, with an adaptation time of 1 minute. Letters were moved centrifugally from the central LED glare source in 0.05 degree steps in each of 8 directions of orientation in succession, separated by 45 degrees. The smallest eccentricity at which the letter could be correctly recognized in 2 of 3 randomized presentations was recorded before the next direction of orientation was assessed. Four letter contrast levels were tested: 1000, 500,100 , and 25 Weber contrast units $\left(C_{w}=\right.$ luminance of 


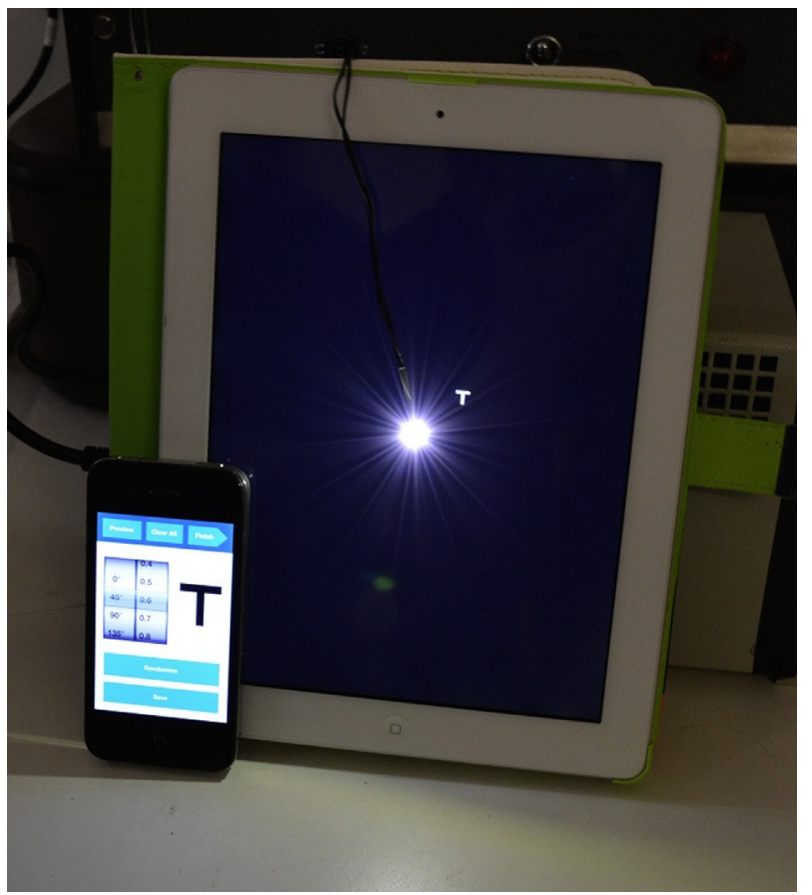

Figure 1. Halometer comprises an LED in the center of an iPad tablet, which is positioned at 2 meters in a dark room. Remote iPhone control via Bluetooth allows the $0.3 \log$ MAR equivalent letters to be moved more eccentric from the central LED glare source in 0.05 degree steps until they are first consistently recognized. This eccentricity is recorded and the assessment repeated in each of the 8 orientations to plot the objective area of obscuration caused by the patient's halo in degrees.

the features minus the luminance of the background divided by the luminance of the background). ${ }^{24}$ The photopic scotoma size was measured in all 8 positions for each of the 4 contrast levels in random order, using a letter height of 0.21 degrees (approximating a $0.3 \log$ MAR letter). This letter height best approximates the driving standard in many countries. $^{25}$

To simulate glare conditions, Bangerter occlusion foils (The Fresnel Prism and Lens Co) were inserted in front of the right eye with the left eye occluded. Occlusion foils contain a series of micro-bubbles, the density of which determines the spread the light. They were developed for optical penalization therapy and were designed to reduce vision in standardized steps from 1.0 to 0.1 designated filters. However, the point spread function of the $0.6,0.4$, and 0.3 foils have been found to be similar, reducing visual acuity by equal amounts, whereas the 0.8 foil spreads light by a lesser degree and so has a reduced effect on visual acuity. ${ }^{26}$ Hence, the 0.8 and 0.6 occlusion foils were used to simulate different levels of light spread on the retina compared with no filter (control), secured within a trial lens plastic housing. Ocular straylight and halometry were measured 3 times each in random sequence with each of the occlusion foils. Straylight and halometry repeatability was assessed at a second subject visit separated by at least 2 hours and by no more than 2 weeks by a second investigator, blinded to the results of the first investigator.

\section{Statistical Analysis}

Repeated measures at each visit were averaged for validity comparison. The area obscured by the halometry glare source was calculated from the eccentricities along the 8 meridians. Because the data for straylight and halometry were normally distributed (1-sample Kolmogrov-Smirnov test $>0.05)$, the influence of the occlusion foils was calculated by use of a 1-way repeated analysis of variance (ANOVA); when significant differences were found, pairwise differences were determined by means of the Bonferroni post hoc test. Intraobserver and interobserver variability was tested for each occlusion foil separately by means of intraclass correlation coefficient, based on a 2-way mixed ANOVA model with a $95 \%$ confidence interval.

\section{RESULTS}

Straylight (measured by use of the straylight meter) increased with the 0.8 occlusion foil (1.48 \pm $0.12 \log [\mathrm{s}])$ compared with no filter $(1.03 \pm 0.21$ $\log [\mathrm{s}] ; P<.001)$, with the 0.6 occlusion foil further increasing $(1.97 \pm 0.18 \log [\mathrm{s}] ; P<.001)$ the straylight $(\mathrm{F}=80.655, P<.001)$.

There was a significant difference in the size of halos measured by use of the different occlusion foils and target contrasts $\left(\mathrm{F}_{1.799}=29.564, P<.001\right.$; Table 1

Table 1. Differences in contrast measured between each Bangerter foil and contrast level $(n=20)$.

\begin{tabular}{|c|c|c|c|c|c|c|c|c|c|}
\hline \multirow[b]{2}{*}{ Filter Letter Contrast } & & \multicolumn{3}{|c|}{ No Filter } & \multicolumn{3}{|c|}{0.8 Bangerter } & \multicolumn{2}{|c|}{ 0.6 Bangerter } \\
\hline & & $500 C_{w}$ & $100 C_{w}$ & $25 C_{w}$ & $1000 C_{w}$ & $500 \mathrm{C}_{\mathrm{w}}$ & $100 C_{w}$ & $1000 C_{w}$ & $500 C_{w}$ \\
\hline \multirow[t]{4}{*}{ No filter } & $1000 C_{w}$ & $P<.001$ & $P<.001$ & $P<.001$ & $P<.001$ & $P<.001$ & $P<.001$ & $P<.001$ & $P<.001$ \\
\hline & $500 \mathrm{C}_{\mathrm{w}}$ & & $P<.001$ & $P<.001$ & $P<.001$ & $P<.001$ & $P<.001$ & $P<.001$ & $P=.001$ \\
\hline & $100 C_{w}$ & & & $P<.001$ & $P=.072$ & $P<.001$ & $P<.001$ & $P<.001$ & $P=.001$ \\
\hline & $25 \mathrm{C}_{\mathrm{w}}$ & & & & $P=1.000$ & $P=.170$ & $P<.001$ & $P=.001$ & $P=.005$ \\
\hline \multirow[t]{3}{*}{0.8 Bangerter } & $1000 C_{w}$ & & & & & $P=.002$ & $P<.001$ & $P=.001$ & $P=.006$ \\
\hline & $500 \mathrm{C}_{\mathrm{w}}$ & & & & & & $P=.001$ & $P=1.000$ & $P=.450$ \\
\hline & $100 \mathrm{C}_{\mathrm{w}}$ & & & & & & & $P=.010$ & $P=1.000$ \\
\hline 0.6 Bangerter & $1000 C_{w}$ & & & & & & & & $P=.300$ \\
\hline
\end{tabular}




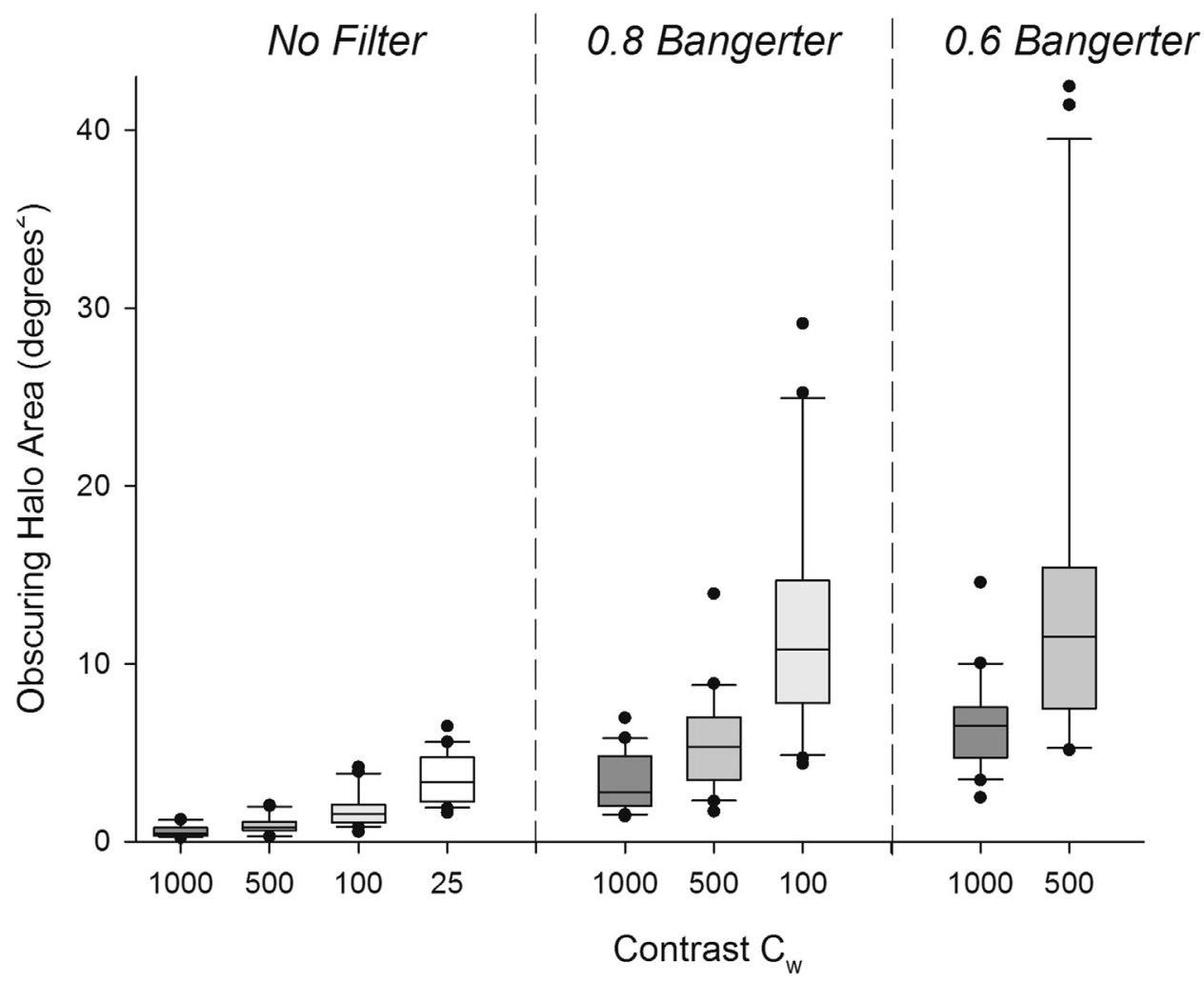

Figure 2. Area of photopic scotoma for each occlusion foil at each contrast level $(n=20)$. Line with box = median; box limits $=1$ standard deviation; error bars $=95 \%$ confidence interval; points $=$ outliers.

and Figure 2). Lower contrast letters showed larger glare-obscured areas, resulting in ceiling effects caused by the screen's field of view.

Intraobserver and interobserver variabilities of the straylight meter and halometer at each contract level with each occlusion foil are presented in Table 2.

\section{DISCUSSION}

Because glare is a major source of visual discontent, ${ }^{22}$ especially with simultaneous image presbyopia corrections, there is a clinical need to quantify this parameter. Hitherto, halometry has been used for this purpose, but, with previous halometers, discrimination and reliability have rarely been assessed, and few techniques allow the halo to be quantified in all directions of gaze, which is a valuable outcome measure for the evaluation of nonconcentric optical designs (Table 1). All instruments that quantify glare assess disability rather than discomfort glare, although these measures are generally correlated. ${ }^{27}$ Light-scatter measurement with the straylight meter does not provide meridional quantification and is not directly related to a regular patient phenomenon with which they are familiar (such as car headlights or street lamps at night). Although straylight meter measurements of forward light scatter have been shown to correlate reasonably strongly with cataract density, ${ }^{28}$ they have been shown to be relatively insensitive to patient-reported glare with refractive IOL designs for presbyopia, although the latter change the optical aberrations as well as scatter light. ${ }^{29}$

As determined by the straylight meter, occlusion foils were shown as an effective method of inducing

Table 2. Intra-observer and inter-observer variability intraclass correlations of the C-Quant and Aston Halometer at each contract level with each Bangerter foil $(n=20)$.

\begin{tabular}{lcccc}
\hline & & \multicolumn{2}{c}{ Aston Halometer } \\
\cline { 3 - 5 } Filter & C-Quant & $1000 \mathrm{C}_{\mathrm{w}}$ & $500 \mathrm{C}_{\mathrm{w}}$ & $100 \mathrm{C}_{\mathrm{w}}$ \\
\hline No filter & $0.875 / 0.774$ & $0.876 / 0.776$ & $0.843 / 0.729$ & $0.775 / 0.632$ \\
0.8 Bangerter foil & $0.871 / 0.499$ & $0.979 / 0.696$ & $0.929 / 0.675$ & $0.874 / 0.532$ \\
0.6 Bangerter foil & $0.873 / 0.845$ & $0.929 / 0.576$ & $0.840 / 0.529$ & \\
\hline $\mathrm{C}_{\mathrm{W}}=$ Weber contrast units. & & & & \\
\hline
\end{tabular}


light scatter in a repeatable way because they have a detrimental effect on the point spread function. ${ }^{26}$ The halometer was able to detect this change in light scatter with high to low contrast letters. The sensitivity appeared to increase with the decreasing contrast of the letter optotypes, but lower-contrast detection of greater glare sources conflicted with the halometer screen's field of view. Decreasing the working distance will mitigate this effect, but at the expense of larger step sizes in optotype position. Although newer tablet technology pixel size is decreasing, having the screen at 2 meters negates the need for a reading addition in pseudophakes or effects of evoking accommodation in the young and therefore was selected as the test working distance. At this distance, the selected letter size of $0.3 \log$ MAR enabled all subjects to identify the letter at the $500 \mathrm{C}_{\mathrm{w}}$ contrast level with the highest light-scattering filter and therefore appeared to be an appropriate setting for the halometer. The effects of dysphotopsia are reported to be most evident during night-driving ${ }^{22}$ and therefore a level of acuity matching that of the typical driving standard was deemed an appropriate size of target for the halometer optotype. $^{25}$

The repeatability of the straylight meter was comparable to that previously demonstrated, ${ }^{23}$ and the halometer repeatability was shown to be similar. Hence, the halometer appears to provide a sensitive, repeatable way of quantifying a patient-recognized form of disability glare in multiple orientations, thus adding a level of objectivity to the subjective reporting of discomfort glare.

\section{WHAT WAS KNOWN}

- Photopic phenomenon, termed dysphotopsia, can result from multifocal IOL implantation.

- The symptom is often described as halos around bright lights, such as driving at night.

\section{WHAT THIS PAPER ADDS}

- An objective technique to determine the size of the halo was validated and shown to be sensitive and repeatable.

\section{REFERENCES}

1. Lackner B, Pieh S, Schmidinger G, Hanselmayer G, Simader C, Reitner A, Skorpik C. Glare and halo phenomena after laser in situ keratomileusis. J Cataract Refract Surg 2003; 29:444-450

2. Gutiérrez R, Jiménez JR, Villa C, Valverde JA, González Anera R. Simple device for quantifying the influence of halos after lasik surgery. J Biomed Opt 2003; 8:663-667
3. van den Berg TJ, Franssen L, Kruijt B, Coppens JE. History of ocular straylight measurement: a review. Z Med Phys 2013; 23:6-20

4. Gruber N, Mosimann UP, Müri RM, Nef T. Vision and night driving abilities of elderly drivers. Traffic Inj Prev 2013; 14:477-485

5. Buznego C, Trattler WB. Presbyopia-correcting intraocular lenses. Curr Opin Ophthalmol 2009; 20:13-18

6. Woodward MA, Randleman JB, Stulting RD. Dissatisfaction after multifocal intraocular lens implantation. J Cataract Refract Surg 2009; 35:992-997

7. Mamalis N, Omar O, Veiga J, Tanner D, Pirayesh A, Fernquist DS. Comparison of two plate-haptic intraocular lenses in a rabbit model. J Cataract Refract Surg 1996; 22:1291-1295

8. Elliot RH. A halometer. Br Med J 1924; 1:624. Available at: http://www.ncbi.nlm.nih.gov/pmc/articles/PMC2304125/pdf/ brmedj05808-0012a.pdf. Accessed September 16, 2015

9. Hunkeler JD, Coffman TM, Paugh J, Lang A, Smith P, Tarantino N. Characterization of visual phenomena with the Array multifocal intraocular lens. J Cataract Refract Surg 2002; 28:1195-1204

10. Boxer Wachler BS, Hiatt D, Chou B, Christie JP. Reduction of pupil size and halos with minus lenses after laser in situ keratomileusis. J Refract Surg 2004; 20:149-154

11. Babizhayev MA, Minasyan H, Richer SP. Cataract halos: a driving hazard in aging populations: implication of the Halometer DG test for assessment of intraocular light scatter. Appl Ergon 2009; 40:545-553

12. Namiki M, Tagami $Y$. [Perimetric glare test and evaluation of intraocular lenses] [Japanese]. Nippon Ganka Gakkai Zasshi 1993; 97:210-216

13. Lee HK, Choe CM, Ma KT, Kim EK. Measurement of contrast sensitivity and glare under mesopic and photopic conditions following wavefront-guided and conventional LASIK surgery. J Refract Surg 2006; 22:647-655

14. Allen R, Ho-Yen GO, Beckingsale AB, Fitzke FW, Sciscio AG, Saleh GM. Post-capsulotomy dysphotopsia in monofocal versus multifocal lenses. Clin Exp Optom 2009; 92:104-109. Available at: http://onlinelibrary.wiley.com/doi/10.1111/j.1444-0938.2008. 00345.x/pdf. Accessed September 16, 2015

15. Lee JH, You YS, Choe CM, Lee ES. Efficacy of brimonidine tartrate $0.2 \%$ ophthalmic solution in reducing halos after laser in situ keratomileusis. J Cataract Refract Surg 2008; 34:963-967

16. Pieh S, Lackner B, Hanselmayer G, Zöhrer R, Sticker M, Weghaupt H, Fercher A, Skorpik C. Halo size under distance and near conditions in refractive multifocal intraocular lenses. $\mathrm{Br}$ J Ophthalmol 2001; 85:816-821. Available at: http://www.ncbi. nlm.nih.gov/pmc/articles/PMC1724058/pdf/v085p00816.pdf. Accessed September 16, 2015

17. Eisenmann D, Jakobi FK, Dick B, Jakobi KW, Pabst W. Untersuchungen zur Blendempfindlichkeit phaker und pseudophaker Augen [Glare sensitivity in patients with phakic and pseudophakic eyes]. Klin Monatsbl Augenheilkd 1996; 208:87-92

18. Dick HB, Krummenauer F, Schwenn O, Krist R, Pfeiffer N. Objective and subjective evaluation of photic phenomena after monofocal and multifocal intraocular lens implantation. Ophthalmology 1999; 106:1878-1886

19. Castro JJ, Jiménez JR, Ortiz C, Alarcón A, Anera RG. New testing software for quantifying discrimination capacity in subjects with ocular pathologies. J Biomed Opt 2011; 16:015001. Available at: http://biomedicaloptics.spiedigitallibrary.org/article. aspx?articleid=1166545. Accessed September 16, 2015

20. Ortiz C, Castro JJ, Alarcón A, Soler M, Anera RG. Quantifying age-related differences in visual-discrimination capacity: drivers 
with and without visual impairment. Appl Ergon 2013; 44:523-531

21. Anera RG, Castro JJ, Jiménez JR, Villa C, Alarcón A. Optical quality and visual discrimination capacity after myopic LASIK with a standard and aspheric ablation profile. J Refract Surg 2011; 27:597-601

22. Mainster MA, Turner PL. Glare's causes, consequences, and clinical challenges after a century of ophthalmic study. Am J Ophthalmol 2012; 153:587-593

23. Cerviño A, Montes-Mico R, Hosking LS. Performance of the compensation comparison method for retinal straylight measurement: effect of patient's age on repeatability. $\mathrm{Br} \mathrm{J}$ Ophthalmol 2008; 92:788-791. Available at: http://bjo.bmj.com/content/92/ 6/788.full.pdf. Accessed September 16, 2015

24. Legge GE. Psychophysics of Reading in Normal and Low Vision. Mahwah, NJ, Lawrence Erlbaum, 2007; 43-67

25. Kiel AW, Butler T, Alwitry A. Visual acuity and legal visual requirement to drive a passenger vehicle. Eye 2003; 17:579582. Available at: http://www.nature.com/eye/journal/v17/n5/ pdf/6700441a.pdf. Accessed September 16, 2015
26. Pérez GA, Archer SM, Artal P. Optical characterization of Bangerter foils. Invest Ophthalmol Vis Sci 2010; 51:609-613. Available at: http://iovs.arvojournals.org/article.aspx?articleid $=2186463$. Accessed September 16, 2015

27. Stringham JM, Garcia PV, Smith PA, McLin LN, Foutch BK. Macular pigment and visual performance in glare: benefits for photostress recovery, disability glare, and visual discomfort. Invest Ophthalmol Vis Sci 2011; 52:7406-7415. Available at: http:// iovs. arvojournals.org/article.aspx?articleid $=2165615$. Accessed September 16, 2015

28. Valbon BF, Alves MR, Ambrósio R Jr. Correlations of straylight, aberrometry, and lens scattering in cataract patients. Rev Bras Oftalmol 2013; 72:244-248. Available at: http://www.scielo.br/ pdf/rbof/v72n4/en_07.pdf. Accessed September 16, 2015

29. Ehmer A, Rabsilber TM, Mannsfeld A, Sanchez MJ, Holzer MP, Auffarth GU. Einfluss verschiedener multifokaler Intraokularlinsenkonzepte auf den Streulichtparameter [Influence of different multifocal intraocular lens concepts on retinal stray light parameters]. Ophthalmologe 2011; 108:952-956 